\title{
Large loss of $\mathrm{CO}_{2}$ in winter observed across pan-arctic permafrost region
}

Authors: Susan. M. Natali ${ }^{1 *} \uparrow$, Jennifer D. Watts ${ }^{1} \uparrow$, Brendan M. Rogers ${ }^{1}$, Stefano Potter ${ }^{1}$, Sarah M. Ludwig ${ }^{1}$, Anne-Katrin Selbmann ${ }^{2}$, Patrick F. Sullivan ${ }^{3}$, Benjamin W. Abbott ${ }^{4}$, Kyle A. Arndt $^{5}$, Leah Birch ${ }^{1}$, Mats P. Björkman ${ }^{6}$, A. Anthony Bloom ${ }^{7}$, Gerardo Celis ${ }^{8}$, Torben R. Christensen $^{9}$, Casper T. Christiansen ${ }^{10}$, Roisin Commane ${ }^{11}$, Elisabeth J. Cooper ${ }^{12}$, Patrick Crill ${ }^{13}$, Claudia Czimczik ${ }^{14}$, Sergey Davydov ${ }^{15}$, Jinyang Du ${ }^{16}$, Jocelyn E. Egan ${ }^{17}$, Bo Elberling ${ }^{18}$, Eugenie S. Euskirchen ${ }^{19}$, Thomas Friborg ${ }^{20}$, Hélène Genet ${ }^{19}$, Mathias Göckede ${ }^{21}$, Jordan P. Goodrich $^{5,22}$, Paul Grogan ${ }^{23}$, Manuel Helbig ${ }^{24}$, Elchin E. Jafarov ${ }^{25}$, Julie D. Jastrow ${ }^{26}$, Aram A. M. Kalhori ${ }^{5}$, Yongwon Kim ${ }^{27}$, John Kimball ${ }^{16}$, Lars Kutzbach $^{28}$, Mark J. Lara ${ }^{29}$, Klaus S. Larsen $^{20}$, Bang-Yong Lee ${ }^{30}$, Zhihua Liu ${ }^{16}$, Michael M. Loranty ${ }^{31}$, Magnus Lund ${ }^{9}$, Massimo Lupascu $^{32}$, Nima Madani ${ }^{7}$, Avni Malhotra ${ }^{33}$, Roser Matamala ${ }^{26}$, Jack McFarland ${ }^{34}$, A. David McGuire $^{19}$, Anders Michelsen ${ }^{35}$, Christina Minions ${ }^{1}$, Walter C. Oechel ${ }^{5,36}$, David Olefeldt ${ }^{37}$, Frans-Jan W. Parmentier ${ }^{38,39}$, Norbert Pirk ${ }^{40}$, Ben Poulter ${ }^{41}$, William Quinton ${ }^{42}$, Fereidoun Rezanezhad $^{43}$, David Risk ${ }^{44}$, Torsten Sachs ${ }^{45}$, Kevin Schaefer ${ }^{46}$, Niels M. Schmidt ${ }^{47}$, Edward A.G. Schuur ${ }^{8}$, Philipp R. Semenchuk ${ }^{48}$, Gaius Shaver ${ }^{49}$, Oliver Sonnentag ${ }^{50}$, Gregory Starr ${ }^{51}$, Claire C. Treat ${ }^{52}$, Mark P. Waldrop ${ }^{34}$, Yihui Wang ${ }^{5}$, Jeffrey Welker ${ }^{53,54}$, Christian Wille ${ }^{45}$, Xiaofeng $\mathrm{Xu}^{5}$, Zhen Zhang ${ }^{55}$, Qianlai Zhuang ${ }^{56}$, Donatella Zona ${ }^{5,57}$

\section{Affiliations:}

${ }^{1}$ Woods Hole Research Center, Falmouth, MA 02540, USA.

2 University of Bayreuth, Bayreuth, Germany.

${ }^{3}$ Environment and Natural Resources Institute, University of Alaska, Anchorage, AK 99508. USA.

${ }^{4}$ Brigham Young University, Department of Plant and Wildlife Sciences, Provo, UT 84062, USA.

${ }^{5}$ Department of Biology, San Diego State University, San Diego, CA 92182, USA.

${ }^{6}$ Department of Earth Sciences, University of Gothenburg, PO Box 460, SE-405 30 Göteborg, Sweden.

7 Jet Propulsion Laboratory, California Institute of Technology, Pasadena, CA 91109, USA.

${ }^{8}$ Center for Ecosystem Science and Society, Northern Arizona University, Flagstaff, AZ 86001, USA.

9 Department of Bioscience, Arctic Research Centre, Aarhus University, Frederiksborgvej 399, 4000 Roskilde, Denmark.

${ }^{10}$ NORCE Norwegian Research Centre, Bjerknes Centre for Climate Research, Bergen, Norway.

11 Dept. of Earth \& Environmental Sciences, Columbia University, NY 10027, USA.

12 Department of Arctic and Marine Biology, Faculty of Biosciences, Fisheries and Economics, UiT. The Arctic University of Norway, N9037 Tromsø, Norway.

${ }^{13}$ Dept. of Geological Sciences and Bolin Centre for Climate Research, Stockholm University, Sweden.

${ }^{14}$ Earth System Science, University of California, Irvine, CA 92697, USA.

15 Northeast Science Station, Pacific Geographical Institute, Cherskii, Russia.

${ }^{16}$ Numerical Terradynamic Simulation Group, W.A. Franke College of Forestry \& Conservation, University of Montana, Missoula, MT 59812, USA.

17 Department of Earth Sciences, Dalhousie University, Halifax, NS, Canada. 
${ }^{18}$ Center for Permafrost (CENPERM), Department of Geosciences and Natural Resource Management, University of Copenhagen, Øster Voldgade 10, DK-1350 Copenhagen, Denmark.

${ }^{19}$ University of Alaska Fairbanks, Institute of Arctic Biology, Fairbanks, AK 99775, USA.

${ }^{20}$ Department of Geosciences and Natural Resource Management, University of Copenhagen, Denmark.

${ }^{21}$ Max Planck Institute for Biogeochemistry, Jena, Germany.

${ }^{22}$ Scripps Institution of Oceanography, UCSD, La Jolla, CA 92037, USA.

${ }^{23}$ Department of Biology, Queen's University, Kingston, ON, Canada.

${ }^{24}$ McMaster University, School of Geography and Earth Sciences, Hamilton, ON, L8S 4K1.

${ }^{25}$ Los Alamos National Laboratory, New Mexico 87545, USA.

${ }^{26}$ Environmental Science Division, Argonne National Laboratory, Argonne, IL 60439, USA.

${ }^{27}$ International Arctic Research Center, University of Alaska Fairbanks, AK 99775, USA.

${ }^{28}$ Institute of Soil Science, Universät Hamburg, Hamburg, Germany.

${ }^{29}$ Department of Plant Biology, University of Illinois, Urbana, IL 61801, USA.

${ }^{30}$ Korea Polar Research Institute (KOPRI), Incheon 21990, Republic of Korea)

${ }^{31}$ Department of Geography, Colgate University, Hamilton, NY 13346, USA.

${ }^{32}$ Department of Geography, National University of Singapore, Singapore.

${ }^{33}$ Environmental Sciences Division and Climate Change Science Institute, Oak Ridge National Laboratory, Oak Ridge, TN 37831, USA.

${ }^{34}$ Geology, Minerals, Energy, and Geophysics Science Center, U.S. Geological Survey, Menlo Park, CA 94025, USA.

${ }^{35}$ Department of Biology, University of Copenhagen, Denmark.

${ }^{36}$ University of Exeter, Exeter, UK.

${ }^{37}$ University of Alberta, Department of Renewable Resources, Edmonton, Alberta, Canada.

${ }^{38}$ Department of Geosciences, University of Oslo, Oslo, Norway.

${ }^{39}$ Department of Physical Geography and Ecosystem Science, Lund University, Lund, Sweden.

${ }^{40}$ Department of Physical Geography and Ecosystem Science, Lund University, Sölvegatan 12, 22362 Lund, Sweden.

${ }^{41}$ NASA GSFC, Biospheric Sciences Lab., Greenbelt, MD 20771, USA.

${ }^{42}$ Wilfrid Laurier University, Waterloo, Ontario, Canada.

${ }^{43}$ Ecohydrology Research Group, Water Institute and Department of Earth \& Environmental Sciences, University of Waterloo, 200 University Avenue West, Waterloo, ON, N2L 3G1, Canada.

${ }^{44}$ St. Francis Xavier University, Antigonish, Nova Scotia, Canada.

${ }^{45}$ GFZ German Research Centre for Geosciences, Telegrafenberg, Potsdam, Germany.

${ }^{46}$ National Snow and Ice Data Center, Boulder, CO 80309, USA.

${ }^{47}$ Arctic Research Centre, Department of Bioscience, Aarhus University, Roskilde, Denmark.

${ }^{48}$ Division of Conservation Biology, Vegetation Ecology and Landscape Ecology, Department of Botany and Biodiversity Research, Rennweg 14, 1030 Vienna, Austria.

${ }^{49}$ The Ecosystems Center, Marine Biological Laboratory, Woods Hole, MA 02543, USA.

${ }^{50}$ Université de Montréal, Département de géographie \& Centre d'études nordiques, 520 chemin de la Côte Sainte Catherine, Montréal, QC H2V 2B8.

${ }^{51}$ Department of Biological Sciences, University of Alabama, Tuscaloosa, AL 35487, USA.

${ }^{52}$ Department of Environmental and Biological Science, University of Eastern Finland, Finland.

${ }^{53}$ Department of Biological Sciences, University of Alaska Anchorage, Anchorage, AK 99508, USA. 
${ }^{54}$ University of Oulu, Finland \& University of the Arctic.

${ }^{55}$ Department of Geographical Sciences, University of Maryland, College Park, MD 20742, USA.

${ }^{56}$ Department of Earth, Atmospheric and Planetary Sciences, Purdue University, West Lafayette, IN 47907, USA.

${ }^{57}$ University of Sheffield, Sheffield, UK.

*Correspondence to: snatali@whrc.org

$\uparrow$ Authors contributed equally to this work. 
Elevated warming in the Arctic, which has been amplified during the winter ${ }^{1-3}$, greatly enhances microbial decomposition of soil organic matter and release of carbon dioxide $\left(\mathrm{CO}_{2}\right)$ from soils ${ }^{4}$. However, the amount of $\mathrm{CO}_{2}$ released in winter is highly uncertain and has not been well represented by ecosystem models or by empirically-based estimates $^{5,6}$. Here we synthesize regional in situ observations of $\mathrm{CO}_{2}$ flux from arctic and boreal soils to assess current and future winter carbon losses from the pan-arctic domain.

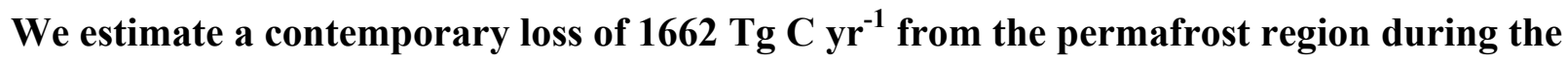
winter season (October through April). This loss is greater than the average growing season carbon uptake for this region estimated from process models $\left(-1032 \mathrm{Tg} \mathrm{C}^{-1}\right)$. Extending model predictions to warmer conditions in 2100 indicates that winter $\mathrm{CO}_{2}$ emissions will increase $17 \%$ under a moderate mitigation scenario-Representative Concentration Pathway (RCP) 4.5-and 41\% under business-as-usual emissions scenario-RCP 8.5. Our results provide a new baseline for winter $\mathrm{CO}_{2}$ emissions from northern terrestrial regions and show enhanced soil $\mathrm{CO}_{2}$ loss due to winter warming may 
Air and soil temperatures in the Arctic are increasing rapidly, with the most severe climate amplification occurring in autumn and winter ${ }^{1,2}$. Although warmer soils decompose more quickly, thus releasing more $\mathrm{CO}_{2}$ into the atmosphere, microbial respiration is known to occur even under extremely cold winter conditions (e.g., down to $\sim-20^{\circ} \mathrm{C}$ ) in the presence of unfrozen microsites that can persist at sub-zero soil temperatures ${ }^{7}$. This production and release of $\mathrm{CO}_{2}$ in winter is expected to increase substantially as soils continue to warm and thaw under a warming climate ${ }^{4,8}$.

However, it remains highly uncertain how much $\mathrm{CO}_{2}$ is currently emitted from the permafrost region during winter ${ }^{9}$ and to what magnitude these emissions might increase in the future $^{8,10}$. Many ecosystem models are not well adapted to characterize respiration from high latitude soils ${ }^{5}$ and may greatly underestimate present and future winter $\mathrm{CO}_{2}$ emissions ${ }^{6}$. Given the limitations in current models, lack of satellite and airborne $\mathrm{CO}_{2}$ data for the Arctic during winter $^{11}$, and gaps in spatial coverage of Arctic air monitoring networks ${ }^{12}$, in situ $\mathrm{CO}_{2}$ flux observations provide the most direct insight into the state of winter $\mathrm{CO}_{2}$ emissions across the northern permafrost domain.

Studies of winter respiration indicate that the amount of $\mathrm{CO}_{2}$ released during cold periods depends greatly on vegetation type ${ }^{13}$, availability of labile carbon substrates ${ }^{14,15,16}$, non-frozen soil moisture $e^{4,7,15,17,18}$, microbial community composition and function ${ }^{19}$, and snow depth ${ }^{15,20,21}$. However, knowledge of the influence of these drivers on the rates and patterns of winter $\mathrm{CO}_{2}$ flux on a regional scale remains limited ${ }^{6,9}$.

Here we present a new compilation of in situ $\mathrm{CO}_{2}$ winter flux data for the northern permafrost domain (Fig. 1, Supplementary Information (SI) Table 1) to examine the drivers and magnitude of winter respiration in the Arctic. We define the winter period as October through 
April - months when the landscape is generally covered by snow and photosynthesis is negligible ${ }^{22,23}$. The dataset represents more than 100 high latitude sites and comprises more than 1,000 aggregated monthly fluxes. We examined patterns and processes driving winter $\mathrm{CO}_{2}$ emissions and scaled fluxes to the permafrost domain using a boosted regression tree (BRT) machine learning model based on hypothesized drivers of winter $\mathrm{CO}_{2}$ flux. Environmental and ecological drivers (e.g., vegetation type and productivity, soil moisture, and soil temperature) obtained from satellite remote sensing and reanalysis data were used to estimate regional winter $\mathrm{CO}_{2}$ emissions for contemporary (2003-2017) climatic conditions. We estimated winter fluxes through 2100 using meteorological and carbon cycle drivers from ensembles of Earth System Model (ESM) outputs for RCP 4.5 and RCP $8.5^{24}$.

Soil temperature had the strongest influence on winter $\mathrm{CO}_{2}$ emissions, with fluxes measured at soil temperatures down to $-20^{\circ} \mathrm{C}$ (Fig. 2a), in line with results from lab incubations (Fig. 2b), demonstrating that microbial respiration can occur in unfrozen microsites that persist at sub-zero bulk soil temperatures ${ }^{18}$. Diffusion of stored $\mathrm{CO}_{2}$ produced during the non-frozen season may have driven some of the emissions measured in winter, but the magnitude of this contribution is unclear. Winter $\mathrm{CO}_{2}$ emissions increased by a factor of $2.9(95 \% \mathrm{CI}=2.1,4.2)$ per $10^{\circ} \mathrm{C}$ soil temperature increase (i.e., Q10) for in situ fluxes and by a factor of $8.5(\mathrm{CI}=5.0$, 14.5) for $\mathrm{CO}_{2}$ release from low temperature lab incubations. Differences between in situ and lab Q10s may reflect site-level differences in environmental drivers other than temperature (in situ and lab sites were not fully overlapping) or variation in the depth of in situ $\mathrm{CO}_{2}$ productionwhich can occur throughout the soil profile-relative to the depth of recorded temperature, which tended to be closer to the soil surface $(\sim 10 \mathrm{~cm})$. 
Air and soil temperatures had the strongest influence on winter flux with a combined relative influence $(\mathrm{RI})$ of $32 \%$. Vegetation type (15\% RI), leaf area index (LAI, 11\%), tree cover (TC; 10\%), and previous summer's gross primary productivity (GPP; $8.5 \%$ ) also influenced winter $\mathrm{CO}_{2}$ emissions (SI Fig. 1). Along with warmer air and soil temperatures in winter and corresponding increases in $\mathrm{CO}_{2}$ loss, summer GPP has also been increasing across the Arctic ${ }^{25}$. The positive relationship between GPP and winter $\mathrm{CO}_{2}$ emissions suggests that increased $\mathrm{CO}_{2}$ uptake during the growing season may be offset, in part, by winter $\mathrm{CO}_{2}$ emissions.

Another important driver of winter respiration was unfrozen water content, which is a function of soil temperature and texture, as finer textured soils contain more unfrozen water than coarse soils for a given sub-zero temperature ${ }^{26}$. Indirect measurements of unfrozen water availability confirm its importance: soils with low sand and high clay content, which tend to have greater unfrozen microsites, were characterized by higher $\mathrm{CO}_{2}$ flux rates. While snow cover is a key driver of winter flux through its impact on ground temperature ${ }^{27}$, remote sensing estimates of snow cover were not significant predictors in the model; this may be a result of high uncertainty in regional snow products or because snow depth and density, which are difficult to determine from space using currently available satellite technology ${ }^{28}$, have a greater influence on ground temperatures than snow presence alone.

Using our model to assess winter flux for the terrestrial permafrost domain, we estimate approximately $1662 \mathrm{Tg} \mathrm{C}$ winter $^{-1}$ released under current climatic conditions (2003-2017), with a corresponding uncertainty of $813 \mathrm{Tg}$ (SI Methods). There were no detected temporal trends in winter $\mathrm{CO}_{2}$ flux during this 15 -year period $(\mathrm{p}>0.1)$, which largely reflects the lack of a significant arctic-wide trend in the reanalysis winter air or soil temperature data used as model inputs $(\mathrm{p}>0.1)$. Although we did not observe region-wide trends during the past 15 years, 
atmospheric $\mathrm{CO}_{2}$ enhancements for Alaska ${ }^{8}$ and site-level studies from Alaskan tundra ${ }^{29,30}$ showed recent increases in winter emissions, which are already shifting some tundra regions from an annual carbon sink to a source.

Our flux estimates are twofold higher than a previous estimate derived from in situ measurements reported in the Regional Carbon Cycle Assessment and Processes (RECCAP) tundra and northern boreal domain ${ }^{10}$, which was based on a much smaller dataset $(<20$ site-years

for winter data). The RECCAP study reported fluxes of $24-41 \mathrm{~g} \mathrm{C} \mathrm{m}^{-2}$ winter ${ }^{-1}$ from in situ data, compared to $64 \mathrm{~g} \mathrm{C} \mathrm{m}^{-2}$ winter ${ }^{-1}$ estimated here for the RECCAP region and $98 \mathrm{~g} \mathrm{C} \mathrm{m}^{-2}$ winter $^{-1}$ for the full permafrost domain (SI Fig. 2). Our estimate of winter flux agrees more closely with the RECCAP atmospheric inversion estimate (27-81 $\mathrm{g} \mathrm{C} \mathrm{m}^{-2}$ winter $\left.^{-1}\right)$, providing some closure between bottom-up and top-down assessments ${ }^{6,12}$.

We then compared our permafrost region flux estimates to winter net ecosystem exchange (NEE) outputs from five process-based terrestrial models and from FluxCom, a global machine-learning NEE product ${ }^{31}$. Our winter $\mathrm{CO}_{2}$ flux estimate was generally higher than estimates from these models, which ranged from $377 \mathrm{Tg} \mathrm{C}^{\mathrm{C}}$ winter $^{-1}$ for FluxCom and from 503 to $1301 \mathrm{Tg} \mathrm{C}$ for the process models (mean: $1008 \mathrm{Tg} \mathrm{C}$ winter $^{-1}$; SI Fig. 3). Similar variation in carbon budget estimates from terrestrial models has been reported elsewhere for high latitude regions $^{5}$ and reflects considerable differences in model parameterization of soil temperature, unfrozen water, and substrate effects on $\mathrm{CO}_{2}$ production under winter conditions. Some processbased models may underestimate winter $\mathrm{CO}_{2}$ emissions simply by erroneously shutting down respiration at sub-zero soil temperatures ${ }^{32}$ or because they are unable to capture small-scale processes that influence winter flux, such as talik formation and shrub-snow interactions that are more likely to be captured by in situ measurements. 
Combining growing season (-687 to $-1647 \mathrm{Tg} \mathrm{C}$ season $^{-1}$ ) and winter NEE derived from

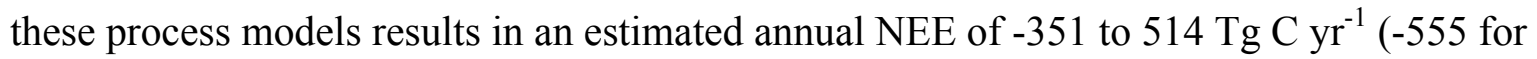

FluxCom; SI Table 2). Because our winter emissions estimate was higher than the process models, we expect that annual $\mathrm{CO}_{2}$ losses may also be higher. For example, if we account for growing season NEE using the process model estimates, this would yield an average annual $\mathrm{CO}_{2}$

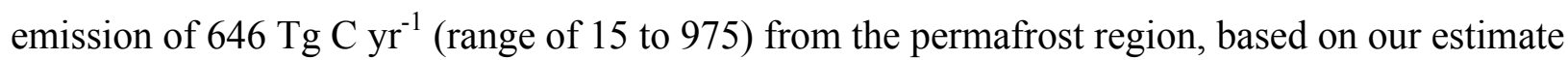
of winter $\mathrm{CO}_{2}$ flux.

Our assessment of future winter emissions_ _ obtained by forcing the BRT model with environmental conditions from CMIP5 ESM outputs ${ }^{2}$ — showed significant increases in winter $\mathrm{CO}_{2}$ emissions under both climate scenarios ( $\mathrm{p}<0.001$, Fig. 3); however, emissions were substantially lower with climate mitigation in RCP 4.5 than with RCP 8.5. Compared to current winter emissions (2003-2017), there was a 17\% projected increase in winter $\mathrm{CO}_{2}$ flux under RCP

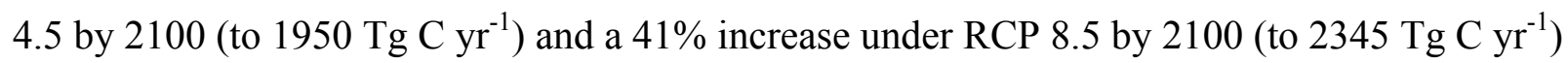
(Fig. 4).

The present-day continuous permafrost zone experienced the strongest positive trend in winter $\mathrm{CO}_{2}$ emissions under both climate scenarios $(\mathrm{p}<0.001)$; however, accounting for differences in area, the largest rate of change occurred across the discontinuous zone (SI Table 3) where soils have warmed rapidly and permafrost has diminished in recent years ${ }^{33}$. The differences in projected changes in winter $\mathrm{CO}_{2}$ emission among permafrost zones may reflect the influence of latitudinal variation in environmental and ecological variables, including tree cover, dominant vegetation, and soil organic matter content and composition ${ }^{34}$.

Increased projected winter $\mathrm{CO}_{2}$ emissions from our data-driven BRT model were largely

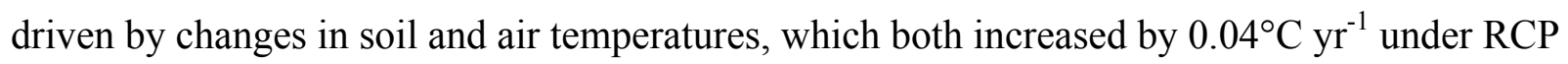




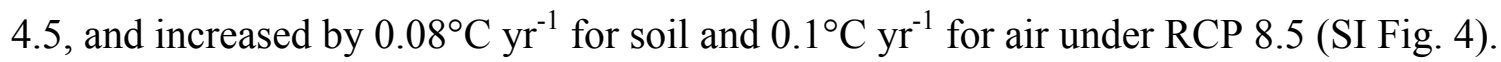
Vegetation leaf area and GPP, both of which were positively related to winter $\mathrm{CO}_{2}$ flux, also significantly increased through 2100 .

From 2018 to 2100, we estimated a cumulative winter flux of 150 Pg C for RCP 4.5 and $162 \mathrm{Pg}$ C for RCP 8.5. This represents an additional $15 \mathrm{Pg}$ C for RCP 4.5 and $27 \mathrm{Pg}$ C for RCP 8.5 emitted as a result of climate change, when compared to the estimated $135 \mathrm{Pg}$ of C that would be emitted through 2100 if current (2003-2017) climatic conditions remained constant. These losses are comparable to $70 \%$ of the current permafrost-region near-surface $(0-30 \mathrm{~cm})$ soil carbon pool $^{35}$. These projected increases are substantially lower than projections from CMIP5 ESMs, in which winter $\mathrm{CO}_{2}$ emissions from ecosystem respiration for the permafrost region $\left(1753 \pm 1066 \mathrm{Pg} \mathrm{C} \mathrm{yr}^{-1}\right.$ for 2003-2005) were projected to increase in 2100 by $37 \%$ and $86 \%$ under RCP 4.5 (2482 $\left.\pm 1403 \mathrm{Pg} \mathrm{C} \mathrm{yr}^{-1}\right)$ and $8.5\left(3473 \pm 1731 \mathrm{Pg} \mathrm{C} \mathrm{yr}^{-1}\right)$, respectively (Fig. 4). Our data-driven BRT model may provide more conservative estimates because current in situ observations may not adequately reflect future environmental responses to substantially warmer winter conditions. However, it is also possible that the ESMs are missing stabilizing drivers and mechanisms that might provide negative feedbacks to winter $\mathrm{CO}_{2}$ emissions. Hence, we stress the importance of addressing current uncertainties in process-model estimates of both growing season and winter $\mathrm{CO}_{2}$ exchange. Given the data limitations during the winter, there is a particular need for long-term monitoring of winter $\mathrm{CO}_{2}$ exchange in permafrost regions to provide key insights into processes that may enhance or mitigate change. As most of the CMIP5 models do not currently include a permafrost component, these data are critical for improving pan-arctic carbon cycle simulations. 
Some of the projected winter $\mathrm{CO}_{2}$ emissions could be offset by plant carbon uptake, which is expected to increase as plants respond favorably to warming and $\mathrm{CO}_{2}$ fertilization ${ }^{36,37}$. In addition, our modeled results do not explicitly account for $\mathrm{CO}_{2}$ uptake during the shoulder seasons (early and late winter period, e.g., October and April), which can occur, even under the snowpack $^{22,23,38}$ and which may increase with climate warming ${ }^{22}$. Our model projections also did not incorporate all changes expected under future climates, such as changes in permafrost distribution, delayed seasonal freeze-up, increased fire frequency, changes in snow cover and distribution, and landscape-level hydrologic changes (e.g., lake drainage).

The $\mathrm{CO}_{2}$ emissions reported here are only part of the winter carbon budget, which also includes significant $\mathrm{CH}_{4}$ emissions from land ${ }^{17,39}$ and $\mathrm{CO}_{2}$ and $\mathrm{CH}_{4}$ emissions from inland waters $^{40}$. Recent data-derived estimates of high-latitude terrestrial winter $\mathrm{CH}_{4}$ emissions range

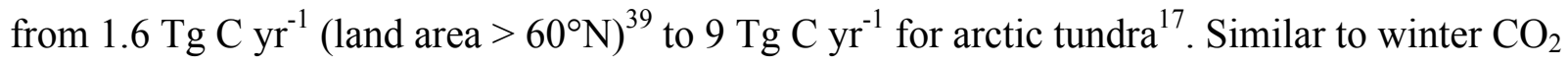
emissions, process models significantly underestimated the fraction of annual $\mathrm{CH}_{4}$ emissions released during the winter ${ }^{39}$.

To reduce uncertainty in estimates of current and future emissions, we recommend increased spatial and temporal coverage and coordination and standardization of in situ winter measurements, improvements to regional snow density products, and development of remote sensing active sensors that can detect high resolution $(<20 \mathrm{~km})$ changes in atmospheric $\mathrm{CO}_{2}$ concentrations during periods of low to no light, which is a key constraint on efforts to monitor changes in permafrost region carbon cycling. Current rates of winter $\mathrm{CO}_{2}$ emissions may be offsetting $\mathrm{CO}_{2}$ uptake by vegetation across the permafrost region. Pan-arctic winter $\mathrm{CO}_{2}$ emissions will likely increase in the near future if Arctic temperatures continue to rise; however, 
278 this positive feedback on global climate can be mitigated with a reduction of global

279 anthropogenic greenhouse gas emissions. 
Methods

$\underline{\text { Data overview }}$

We compiled a dataset of in situ winter season (Oct-April) $\mathrm{CO}_{2}$ emissions and potential driving variables from sites within the northern permafrost zone ${ }^{41}$. The synthesized dataset included 66 published studies and 21 unpublished studies (SI Table 1) conducted at 104 sites (i.e., sample areas with unique geographic coordinates) and in 152 sampling locations (i.e., different locations within a site as distinguished by vegetation type, landscape position, etc.). Sites spanned boreal and tundra landcover classes (SI Fig. 5, SI Table 4) in continuous permafrost $(n=69)$, discontinuous $(n=24)$, and isolated/sporadic $(n=11)$ permafrost zones (Fig. 1). Data were aggregated at the monthly level; however, the number of measurements per month varied among studies. The dataset included more than 1,000 site-month flux measurements. We also extracted $\mathrm{CO}_{2}$ data from incubations of permafrost-region soils (SI Table 5) to compare their temperature response functions (Q10) with Q10 derived from the synthesized in situ flux data. Further details of data extraction and Q10 calculations can be found in the Supplementary Methods.

\section{Data extraction, geospatial data}

We extracted data from regional gridded geospatial products including climatological data, soil temperature and moisture, snow water equivalent, soil carbon stocks and texture, permafrost status, vegetation cover, proxies of vegetation growth and productivity (e.g., enhanced vegetation index, EVI; leaf area index, LAI; gross primary productivity, GPP). See Supplementary Methods for further description and data sources. All geospatial data were re- 
gridded to the National Snow and Ice Data Center Equal Area Scalable Earth (EASE) 2.0 format ${ }^{42}$ at a $25-\mathrm{km}$ spatial resolution prior to the $\mathrm{CO}_{2}$ flux upscaling and simulations.

\section{Boosted regression tree analysis}

We used boosted regression tree analysis (BRT) to model drivers of winter $\mathrm{CO}_{2}$ emissions and to upscale emissions to the pan-arctic region under current and future climate scenarios. The BRT model was fit in $\mathrm{R}^{43}$ using 'gbm' package version $2.1 .1^{44}$, and using code adapted from ${ }^{45}$. The BRT model was fitted with the following metaparameters: Gaussian error distribution, bag-fraction (i.e., proportion of data used in each iteration) of 0.5 , learning rate (contribution of each tree to the final model) of 0.005 , and a tree complexity (maximum level of interactions) of two. We used 10-fold cross-validation (CV) to determine the optimal number of trees to achieve minimum predictive error and to fit the final model to the data.

We used geospatial data as explanatory variables in our BRT model (See Supplementary Methods for full description of input data). We removed highly correlated variables from the models (Spearman $\rho=0.7$ ), retaining the variable within each functional category (e.g., air temperature) that had the highest correlation with winter flux. We further reduced the model by removing variables in reverse order of their relative influence, until further removal resulted in a $2 \%$ average increase in predictive deviance. We compared this model with one in which we included site level in situ data as explanatory variables. We used the geospatial model because it allowed us to upscale results and because the percent deviance (SI Table 6) and driving variables (SI Fig. 1) were similar between models.

We assessed BRT model performance using: 1. The correlation between predicted and observed values using the $\mathrm{CV}$ data (i.e., data withheld from model fitting), hereafter referred to 
as the CV correlation, and; 2. deviance explained by the model over the evaluation dataset (i.e.,

$326 \mathrm{CV}$ data), calculated as: \% deviance $=(\mathrm{CV}$ null deviance $-\mathrm{CV}$ residual deviance $) / \mathrm{CV}$ null

327 deviance *100. Further details of the BRT models can be found in the Supplementary Methods.

328 We obtained an estimate of model uncertainty by first obtaining the average internal root 329 mean squared error (RMSE; $0.21 \mathrm{~g} \mathrm{C} \mathrm{m}^{-2} \mathrm{~d}^{-1}$ ) for the ensemble of boosted regression trees. We 330 then made the assumption that this error applied equally to all grid cell areas within the domain. 331 Scaling this error to the full domain $\left(16.95 \times 10^{6} \mathrm{~km}^{2}\right)$ and by the total number of days for the $332 \quad$ winter (October through April) period provided us with a winter flux error of $813 \mathrm{Tg}$ C.

\section{Spatial and temporal domain for mapping}

We scaled the modeled flux data to the northern permafrost land area $\geq 49^{\circ} \mathrm{N}^{41}$, which comprises $16.95 \times 10^{6} \mathrm{~km}^{2}$ of tundra and boreal lands (excludes glaciers, ice sheets, and barren lands; Fig. 1) with lake area removed. We defined the winter period as the months of October through April. Because the climate within this timeframe varies substantially across the permafrost zone, this month-based definition, while temporally consistent, may include some areas that are influenced by climate that would fall outside expected winter temperature ranges. Therefore, in a separate approach (presented in the Supplementary Method), we defined winter based on soil temperature, but we did not find substantial differences in regional flux budgets when using the two approaches (temperature-defined winter flux was $\sim 5 \%$ higher, 1,743 Tg C, than when using the month-based winter period).

\section{Spatial upscaling of fluxes}


The BRT model was applied at a monthly time step from 2003 through 2017. For each

month, the map predictions were applied to a raster stack of input predictors using the $\mathrm{R}$ 'dismo' package $^{46}$ for interface with the 'gbm' package and the 'raster' v2.6-7 predict function for geospatial model applications. A n.tree (\# of trees) of 1,000 was selected for each model run. Output monthly mean estimates of daily $\mathrm{CO}_{2}$ flux $\left(\mathrm{g} \mathrm{CO}_{2}-\mathrm{C} \mathrm{m}^{-2} \mathrm{~d}^{-1}\right)$ were generated for each 25$\mathrm{km}$ grid cell. Total pan-arctic $\mathrm{CO}_{2}$ flux was obtained on a monthly basis by first calculating the terrestrial area for each grid cell by subtracting lake fractions (MODIS satellite product MOD44W) from each grid cell area. The fluxes were then scaled according to days per month and terrestrial area to obtain per grid cell totals.

We analyzed the pan-arctic flux data for annual temporal trends using the nonparametric Mann-Kendall test, which was run in the R 'zyp' package ${ }^{47}$ with pre-whitening (Yue and Pilon method) to remove autocorrelation. We report Kendall's correlation coefficient, $\tau$, to describe the strength of the time-series and Theil-Sen slope to describe trends over time.

\section{Comparison of BRT estimates with process-based models}

We compared our regional winter flux estimates to: 1) outputs from five process-based terrestrial models estimated for the northern permafrost domain: National Center for Atmospheric Research (NCAR) Community Land Model (CLM) versions 4.5 and 5; LundPotsdam-Jena Dynamic Global Vegetation Model (LPJ-DGVM), Wald Schnee und Landscraft version (LPJ-wsl); CARbon DAta MOdel FraMework (CARDAMOM); and the NASA SMAP Level 4 Carbon (L4C) Version 3 product; 2) estimates for the northern permafrost domain derived from FluxCom, a global gridded machine-learning net ecosystem exchange (NEE) product; and 3) four process-based terrestrial models and eight atmospheric inversion models 
from the high latitude model intercomparison for the Regional Carbon Cycle Assessment and Processes (RECCAP) tundra and northern boreal domain ${ }^{10}$. See Supplementary Methods for further description of these models.

\section{$\underline{\text { Projected } \mathrm{CO}_{2} \text { flux }}$}

Inputs for the BRT model of future scenarios of winter $\mathrm{CO}_{2}$ flux were obtained from ensembles of Earth System Model (ESM) outputs from the Fifth Coupled Model Intercomparison Project (CMIP5) for RCP 4.5 and $8.5^{2}$. Inputs included: 1) Annual GPP; 2) mean annual summer LAI (July \& August); 3) mean summer soil moisture (June, July, August); 4) mean monthly soil moisture; 5) mean monthly near-surface (2 m) air temperature; and 6) mean monthly soil temperature (layer 1) (SI Table 7). Ensemble mean RCP 4.5 and 8.5 predictor fields were bias-corrected using the delta, or perturbation method ${ }^{48}$, based on historic ESM outputs and observed historical data and re-projected to EASE2 $25 \mathrm{~km}$ grids.

In addition to the $0.21 \mathrm{~g} \mathrm{C} \mathrm{m}^{-2} \mathrm{~d}^{-1}$ error obtained based on the BRT model RMSE, we used the outcome from bootstrapped BRT model simulations to estimate additional, inherit prediction variability in the machine learning outcomes for current and future $\mathrm{CO}_{2}$ emissions ${ }^{49}$ (see Supplementary Information).

For the CMIP5 RCP 4.5 and 8.5 simulations of respiration, we used an r1i1p1 ensemble mean from 15 models (see Supplementary Information). 
Data Availability: Data are archived and freely available at the ORNL Distributed Active Archive Center (DAAC). The synthesis dataset will be available at

Supplementary Information includes Supplementary Methods, Supplementary Tables 1-8, and Supplementary Figures 1-6.

Correspondence and requests for materials should be addressed to S.M.N.

Acknowledgements: This study was supported by funding from NASA's Arctic-Boreal Vulnerability Experiment (ABoVE; \#NNX15AT81A to S.M.N.), with additional funding from NASA NIP (NNX17AF16G TO J.D.W.), NSF (\#955713 and \#1331083 to E.A.G.S.; \# 1503559 to E.E.J.), the Next-Generation Ecosystem Experiments Arctic project, DOE Office of Science (E.E.J.), and funding that supported the data that were included in this synthesis.

Author contributions: S.M.N., J.D.W., and B.M.R conceived the work. B.W.A., G.C., C.T.C., H.G., E.E.J., M.M.L., S.M.L., M.L., A.M., C.M., S.M.N., F.R., B.M.R., K.S., A.S., C.C.T., Y.W., and X.X. extracted unpublished data. K.A.A, M.P.B, G.C, T.R.C, E.J.C, C.C., S.D., J.D., J.E.E., B.E., E.S.E., T.F., M.G., J.P.G., P.G., M.H., J.D.J., A.A.A.K., Y.K., L.K., K.S.L., M.L., R.M., J.M., A.M., S.M.N., W.C.O., F.W.P., N.P., W.Q., D.R., T.S., N.M.S., E.A.G.S, P.R.S., 
412 O.S., P.F.S., M.P.W., C.W., and D.Z. provided unpublished or raw data. L.B., A.A.B., J.D., 413 J.S.K., Z.L., N.M., A.D.M., B.P., and Z.Z. provided modeled data/results. S.M.L., C.M., S.M.N., 414 S.P., and J.D.W. prepared tables and figures. G.C., H.G., M.J.L., M.M.L., S.M.L, S.M.N., S.P., 415 B.M.R., P.F.S., and J.D.W. performed statistical analyses, including BRT modeling. S.P., 416 B.M.R., and J.W. led the BRT upscaling or projection analyses. All authors contributed to data 417 interpretation and preparation of manuscript text.

418 

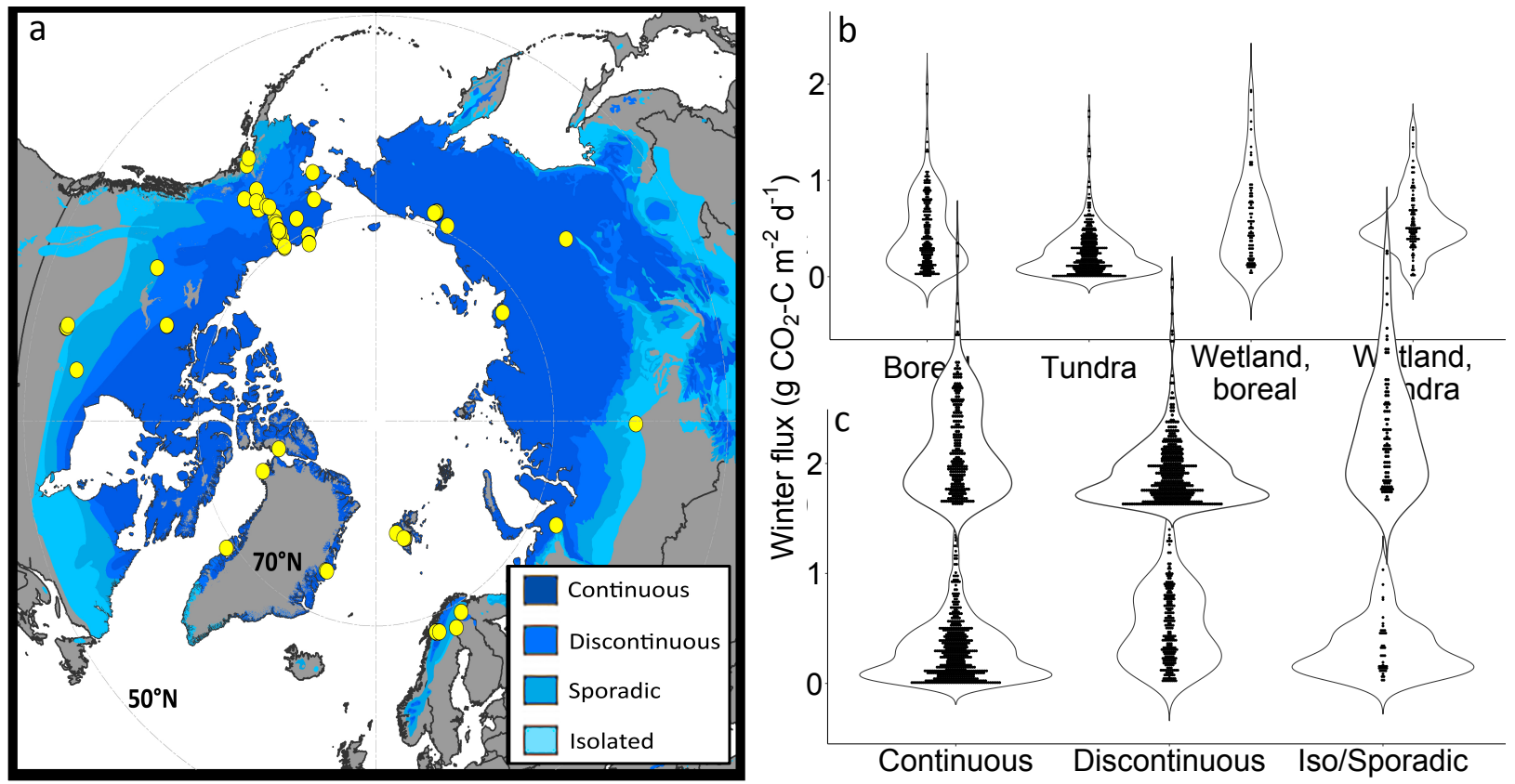

Fig. 1. Distribution of in situ data included in this winter $\mathrm{CO}_{2}$ flux synthesis. (a) Locations of in situ winter $\mathrm{CO}_{2}$ flux data (yellow circles) in this synthesis included (b) upland and wetland sites in boreal and tundra biomes located (c) within the northern permafrost region ${ }^{41}$. Violin plots $(b, c)$ depict magnitude and distribution density (width; dots are monthly aggregated data) of in situ data used in our machine-learning model. 

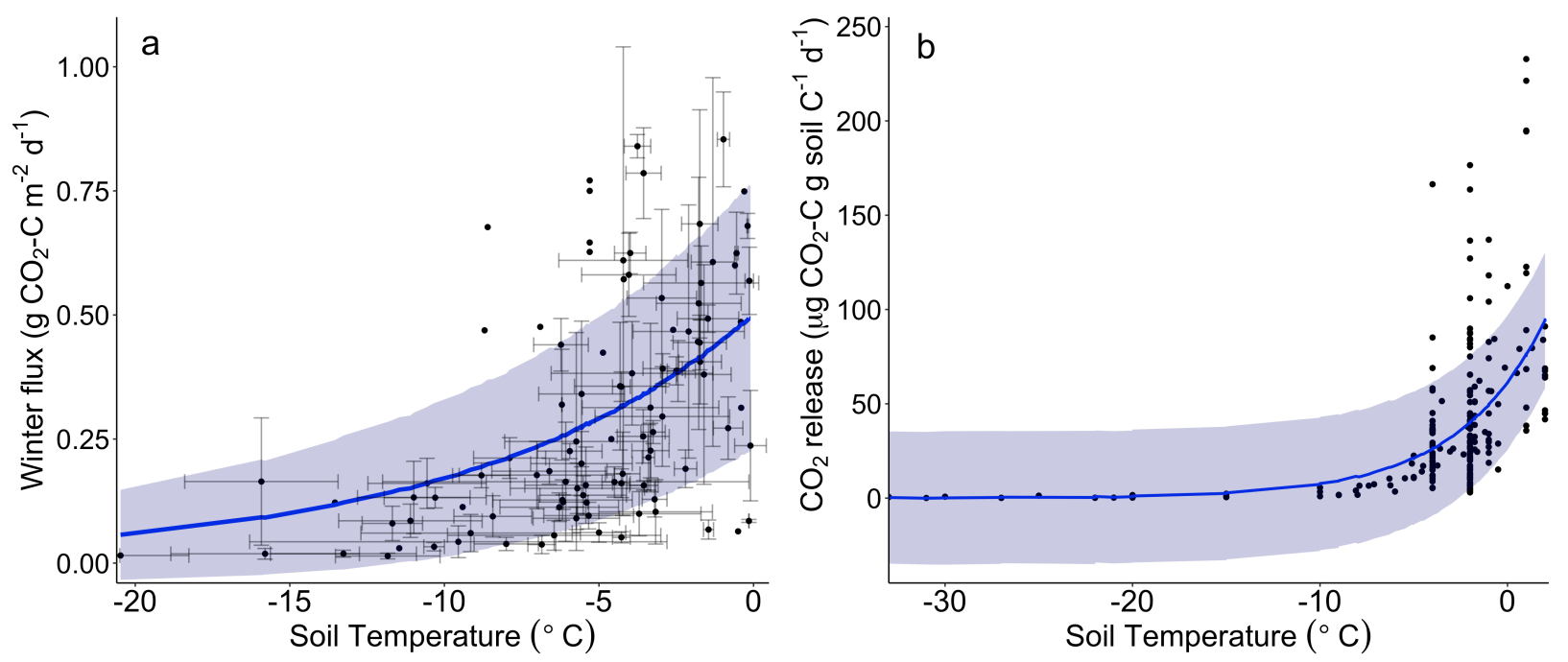

Fig. 2. Effect of soil temperature on $\mathrm{CO}_{2}$ release from soils. (a) Relationships between in situ soil temperature $\left(\sim 10 \mathrm{~cm}\right.$ average depth) and $\mathrm{CO}_{2}$ fluxes and (b) temperature and $\mathrm{CO}_{2}$ released from lab incubations. Shading represents the standard deviation of an exponential model, which, for in situ fluxes, was fit to mean $\mathrm{CO}_{2}$ flux from each sample location (symbols shown with standard error). Note that the different soil temperature scales between panels reflect data ranges. 

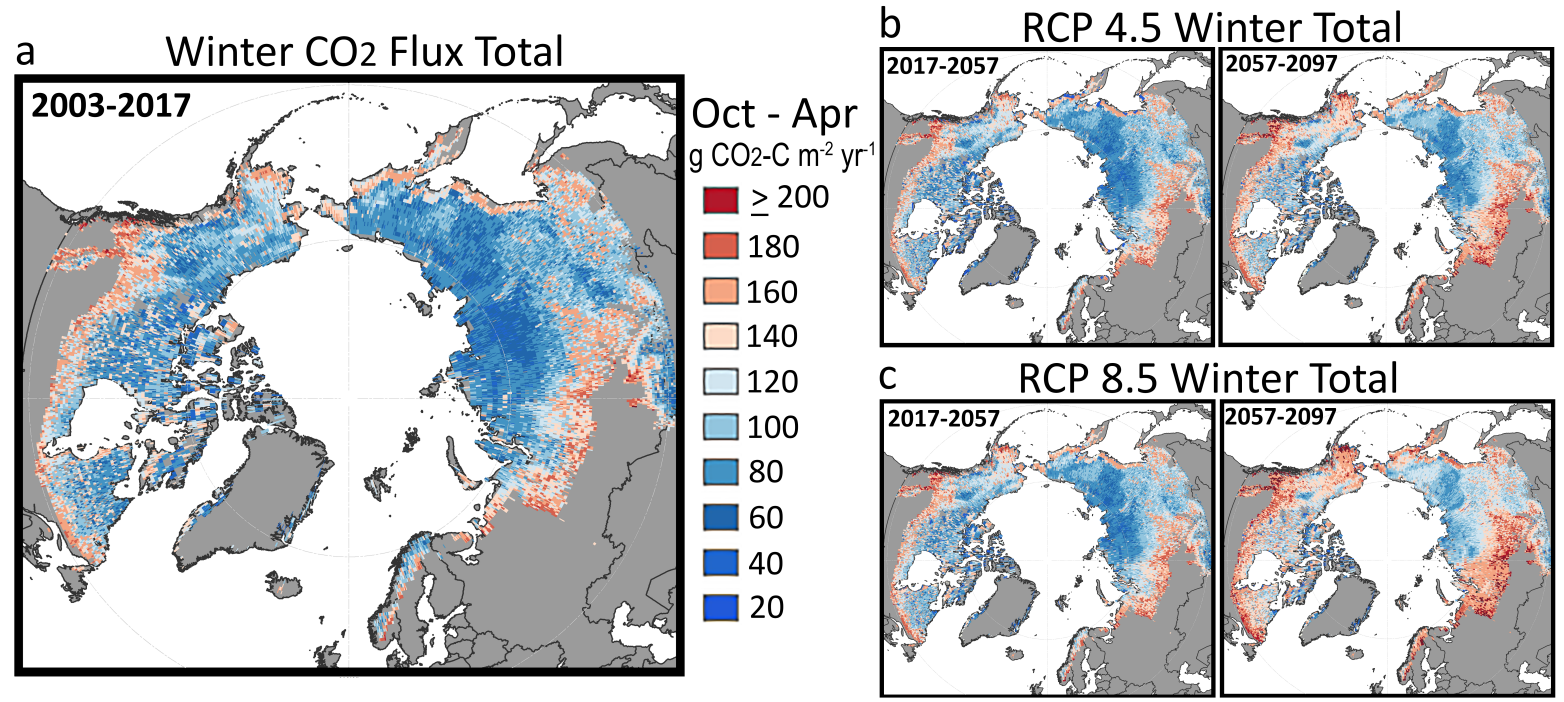

Fig. 3. Pan-Arctic winter $\mathrm{CO}_{2}$ emissions under current and future climate scenarios. (a)

Average annual winter (October - April) $\mathrm{CO}_{2}$ emissions estimated for the permafrost region for basis $\left(\mathrm{g} \mathrm{CO}_{2}-\mathrm{C} \mathrm{m}^{-2} \mathrm{yr}^{-1}\right)$. 
444

445

446

447

448

449

450

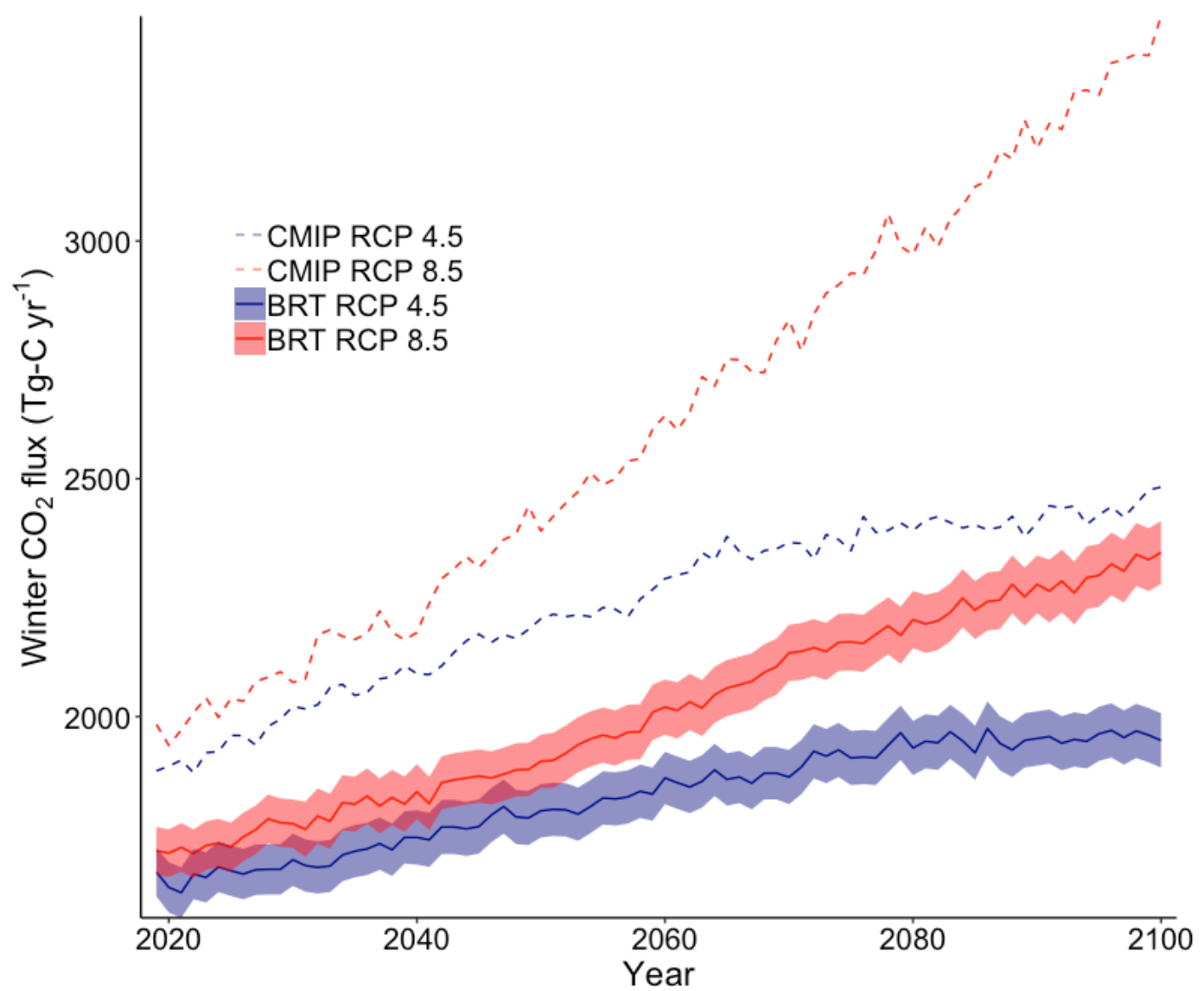

Fig. 4. Projected annual $\mathrm{CO}_{2}$ emissions during the winter for the northern permafrost region. Solid lines represent BRT modeled results through 2100 under RCP 4.5 (red solid line) and RCP 8.5 (blue solid line), with bootstrapped 95\% confidence intervals indicated by shading. For reference, CMIP5 ensemble respiration for RCP 4.5 and 8.5 are also shown (dashed lines). 


\section{References}

$1 \quad$ Huang, J. Recently amplified arctic warming has contributed to a continual global warming trend. Nat. Clim. Change 7, 875-879 (2017).

2 Koenigk, T. et. al. Arctic climate change in 21st century CMIP5 simulations with ECEarth. Clim. Dyn. 40, 2719-2743 (2013).

3 Cohen, J., Screen, J.A., Furtado, J.C., Barlow, M., et al. Recent Arctic amplification and extreme mid-latitude weather. Nature Geosci. 7, 627-637 (2014).

4 Schadel, C., Bader, M.K-F., Schuur, E.A.G., Biasi, C., Bracho, R. et al. Potential carbon emissions dominated by carbon dioxide from thawed permafrost soils. Nat. Clim. Change 6, 950-953 (2016).

5 Fisher, J. B. et. al. Carbon cycle uncertainty in the Alaskan Arctic. Biogeosciences 11, 4271-4288 (2014).

6 Commane, R., Lindaas, J., Benmergui, J., Luus, K.A., et al. Carbon dioxide sources from Alaska driven by increasing early winter respiration from Arctic tundra. Proc. Natl. Acad. Sci. 114, 5361-5366 (2017).

7 Elberling, B., Brandt, K.K. Uncoupling of microbial $\mathrm{CO}_{2}$ production and release in frozen soil and its implications for field studies of arctic C cycling. Soil Biol. Biogeochem. 35, 263-272 (2003).

8 Schuur, E. A. G., McGuire, A.D., Schadel, C., Grosse, G., et al. Climate change and the permafrost carbon feedback. Nature 520, 171-179 (2015).

9 Belshe, E. F., Schuur, E.A.G., Bolker, B.M. Tundra ecosystems observed to be $\mathrm{CO}_{2}$ sources due to differential amplification of the carbon cycle. Ecology Lett. 16, 1307-1315 (2013).

10 McGuire, A. D. et. al. An assessment of the carbon balance of Arctic tundra: Comparisons among observations, process models, and atmospheric inversions. Biogeosciences 9, 3185-3204 (2012).

11 Schimel, D., Pavlick, R., Fisher, J.B., Asner, G.P. et al. Observing terrestrial ecossytems and the carbon cycle from space. Glob.Change Biol. 21, 1762-1776 (2014).

12 Parazoo, N., Commane, R., Wofsy, S.C., Koven, C.D. Detecting regional patterns of changing CO2 flux in Alaska. Proc. Natl. Acad. Sci. 113, 7733-7738 (2016).

13 Grogan, P. Cold season respiration across a Low Arctic landscape: The influence of vegetation type, snow depth, and interannual climatic variation. Arctic, Antarct. Alp. Res. 44, 446-456 (2012).

14 Michaelson, G. J., Ping, C.L. Soil organic carbon and $\mathrm{CO}_{2}$ respiration at subzero temperature in soils of Arctic Alaska. J.G.R. Atmos. 108 (2005).

15 Rogers, M. C., Sullivan, P.F., Welker, J.M. Evidence of nonlinearity in the response of net ecosystem $\mathrm{CO}_{2}$ exchange to increasing levels of winter snow depth in the high Arctic of Northwestern Greenland. Arct. Antarc. Alpine Res. 43, 95-106 (2011).

16 Wang, T., Ciais, P., Piao, S.L., Ottle, C., et al. Controls on winter ecosystem respiration in temperate and boreal ecosystems. Biogeosciences 8, 2009-2025 (2011).

17 Zona, D., Gioli, B., Commane, R., Lindaas, J., et al. Cold season emissions dominate the Arctic tundra methane budget. Proc. Natl. Acad. Sci. 113, 40-45 (2016).

18 Schaefer, K. J., et al. A parameterization of respiration in frozen soils based on substrate availability. Biogeosciences 13, 1991-2001 (2016). 
19 Monson, R., Lipson, D., Burns, S.P., Turnipseed, A.A., et al. Winter forest soil respiration controlled by climate and microbial community composition. Nature 439, 711-714 (2006).

20 Welker, J. M., Fahnestock, J.T., Jones, M.H. Annual $\mathrm{CO}_{2}$ flux in dry and moist arctic tundra: field responses to increases in summer temperatures and winter snow depth. . Clim. Chan 44, 139-150 (2000).

21 Natali, S. M., Schuur, E.A.G., Trucco, C., Hicks Pries, C.E., et al. Effects of experimental warming of air, soil and permafrost on carbon balance in Alaskan tundra. Glob. Chan. Biol. 17, 1394-1407 (2011).

22 Webb, E. E., et. al. Increased wintertime $\mathrm{CO}_{2}$ loss as a result of sustained tundra warming. Biogeosciences 121, 1-17 (2016).

23 Christiansen, C. T., Schmidt, N. M. \& Michelsen, A. High Arctic dry heath $\mathrm{CO}_{2}$ exchange during the early cold season. Ecosystems 15, 1083-1092 (2012).

24 Knutti, R., Masson, D. \& Gettelman, A. Climate model genealogy: Generation CMIP5 and how we got there. Geophys. Res. Lett. 40, 1194-1199 (2013).

25 Forkel, M., et. al. Enhanced seasonal $\mathrm{CO}_{2}$ exchange caused by amplified plant productivity in northern ecosystems. Science 351, 696-699 (2016).

26 Tucker, C. Reduction of air- and liquid water-filled soil pore space with freezing explains high temperature sensitivity of soil respiration below 0 degrees C. Soil Biol. Biochem. 78, 90-96 (2014).

27 Huang, Y., Jiang, J., Ma, S., Ricciuto, D., Hanson, P.J., Luo, Y. Soil thermal dynamics, snow cover, and frozen depth under five temperature treatments in an ombrotrophic bog: constrained forecast with data assimilation. J.G.R. Biogeosci. 122, 2046-2063 (2017).

28 Witze, A. Snow-sensing fleet to unlock water's icy secrets. Nature 7, 1, doi:doi: 10.1038/532017a (2016).

29 Natali, S. M., Schuur, E.A.G., Mauritz, M., Schade, J.D., et al. Permafrost thaw and soil moisture driving $\mathrm{CO}_{2}$ and $\mathrm{CH}_{4}$ release from upland tundra. J.G.R. Biogeosci. 120, 525537 (2015).

30 Euskirchen, E. S., Bret-Harte, M. S., Shaver, G. R., Edgar, C. W., Romanovsky, V. E. Long-term release of carbon dioxide from arctic tundra ecosystems in Alaska. . Ecosystems 20, 960-974 (2017).

31 Tramontana, G., et. al. Predicting carbon dioxide and energy fluxes across global FLUXNET sites with regression algorithms. Biogeosciences 13, 4291-4313 (2016).

32 Koven, C. D., et. al. Permafrost carbon-climate feedbacks accelerate global warming. Proc. Natl. Acad. Sci. 108, 14769-14774 (2011).

33 Slater, A. G., \& Lawrence, D.M. Diagnosing present and future permafrost from climate models. . J. Climate 26, 5608-5623 (2013).

34 Vanhala, P., K. Karhu, M. Tuomi, K. Bjorklof, H. Fritze, J. Liski. Temperature sensitivity of soil organic matter decomposition in southern and northern areas of the boreal forest zone. Soil Biol. Biochem. 40, 1758-1764 (2008).

35 Hugelius, G. e. a. Estimated stocks of circumpolar permafrost carbon with quantified uncertainty ranges and identified data gaps. . Biogeosciences 11, 6573-6593 (2014).

36 McGuire, A. D., et. al. Dependence of the evolution of carbon dynamics in the northern permafrost region on the trajectory of climate change. Proc. Natl. Acad. Sci., doi:doi:10.1073/pnas.1719903115 (2018). 
37 Qian, H., Joseph, R., Zeng, N. Enhanced terrestrial carbon uptake in the Northern High Latitudes in the 21st century from the Coupled Carbon Climate Model Intercomparison Project model projections. Glob. Chan. Biol. 16, 641-656, doi:10.1111/j.13652486.2009.01989.x.

38 Starr, G. O., et. al. Photosynthesis of Arctic evergreens under snow: Implications for tundra ecosystem carbon balance. Ecology 84, 1415-1420 (2003).

39 Treat, C. C., Bloom, A. A. \& Marushchak, M. E. Nongrowing season methane emissions-a significant component of annual emissions across northern ecosystems. . Glob. Chang. Biol. 24, 3331-3343 (2018).

\section{Methods References}

40 Walter Anthony, K., et. al. 21st-century modeled permafrost carbon emissions accelerated by abrupt thaw beneath lakes. Nat. Commun. 9 (2018).

41 Brown, J., Ferrians, O., Heginbottom, J. \& Melnikov, E. Circum-Arctic map of permafrost and ground-ice conditions, version 2. (2002).

42 Brodzik, M. J., Billingsley, B., Haran, T., Raup, B. \& Savoie, M. H. EASE-Grid 2.0: Incremental but significant improvements for Earth-gridded data sets. ISPRS Int. J. GeoInformation 1, 32-45 (2012).

43 Team., R. C. R: A language and environment for statistical computing. (2016).

44 Ridgeway, G. Generalized Boosted Models: A guide to the gbm package. 1-12 (2007).

45 Elith, J., Leathwick, J. R. \& Hastie, T. A working guide to boosted regression trees. $J$. Anim. Ecol., 802-813 (2008).

46 Hijmans, R. J., Phillips, S., Leathwick, J. \& Elith, J. . R “dismo” package. (2017).

47 Bronaugh, D. W. R "zyp" trends package. (2017).

48 Rogers, B. M., et. al. Impacts of climate change on fire regimes and carbon stocks of the U.S. Pacific Northwest. J. Geophys. Res. Biogeosciences 116 (2011).

49 Leathwick, J. R., Elith, J., Francis, M. P., Hastie, T. \& Taylor, P. Variation in demersal fish species richness in the oceans surrounding New Zealand: An analysis using boosted regression trees. Mar. Ecol. Prog. Ser. 321, 267-281 (2006). 